\title{
Estradiol inhibits the effects of extracellular ATP in human sperm by a non genomic mechanism of action
}

\author{
Marco Rossato $^{1}$, Marco Ferigo ${ }^{2}$, Carlo Galeazzi ${ }^{2} \&$ Carlo Foresta ${ }^{2}$ \\ ${ }^{1}$ Department of Medical and Surgical Sciences, Clinica Medica 3, University of Padova, Italy; ${ }^{2}$ Department of \\ Histology, Microbiology and Medical Biotechnologies, Center of Male Gamete Cryopreservation, University \\ of Padova, Padova, Italy
}

Received 18 March 2005; accepted in revised form 20 July 2005

Key words: ATP, calcium, estradiol, human sperm, membrane potential, $\mathrm{P} 2$ purinergic receptor

\begin{abstract}
Steroid hormones, beside their classical genomic mechanism of action, exert rapid, non genomic effects in different cell types. These effects are mediated by still poorly characterized plasma membrane receptors that appear to be distinct from the classic intracellular receptors. In the present study we evaluated the non genomic effects of estradiol $\left(17 \beta \mathrm{E}_{2}\right)$ in human sperm and its effects on sperm stimulation by extracellular ATP, a potent activator of sperm acrosome reaction. In human sperm $17 \beta \mathrm{E}_{2}$ induced a rapid increase of intracellular calcium $\left(\mathrm{Ca}^{2+}\right)$ concentrations dependent on an influx of $\mathrm{Ca}^{2+}$ from the extracellular medium. The monitoring of the plasma membrane potential variations induced by $17 \beta \mathrm{E}_{2}$ showed that this steroid induces a rapid plasma membrane hyperpolarization that was dependent on the presence of $\mathrm{Ca}^{2+}$ in the extracellular medium since it was absent in $\mathrm{Ca}^{2+}$ free-medium. When sperm were pre-incubated in the presence of the $\mathrm{K}^{+}$channel inhibitor tetra-ethylammonium, the $17 \beta \mathrm{E}_{2}$ induced plasma membrane hyperpolarization was blunted suggesting the involvement of $\mathrm{K}^{+}$channels in the hyperpolarizing effects of $17 \beta \mathrm{E}_{2}$. Extracellular ATP induced a rapid plasma membrane depolarization followed by acrosome reaction. Sperm preincubation with $17 \beta \mathrm{E}_{2}$ inhibited the effects of extracellular ATP on sperm plasma membrane potential variations and acrosome reaction. The effects of $17 \beta \mathrm{E}_{2}$ were specific since its inactive steroisomer $17 \alpha \mathrm{E}_{2}$ was inactive. Furthermore the effects of $17 \beta \mathrm{E}_{2}$ were not inhibited by tamoxifen, an antagonist of the classic $17 \beta \mathrm{E}_{2}$ intracellular receptor.
\end{abstract}

\section{Introduction}

Several recent studies have reported that steroid hormones exert important effects in human sperm through a non genomic mechanism of action by interacting with specific binding sites/receptors present on sperm plasma membrane [1-4]. In particular progesterone has been shown to induce an influx of $\mathrm{Ca}^{2+}$ and $\mathrm{Na}^{+}$within sperm cytoplasm determining a rapid rise in $\left[\mathrm{Ca}^{2+}\right]_{\mathrm{i}}$ and plasma membrane depolarization [5-7]. These effects were followed by acrosome reaction, a biological event that is fundamental for sperm-oocyte interaction [8]. More recently estradiol $\left(17 \beta \mathrm{E}_{2}\right)$, another steroid present at high concentration in follicular fluid from ovulatory follicles together with progesterone [9], has been shown to possess specific binding sites on human sperm plasma membrane [10] and it has been demonstrated that $17 \beta \mathrm{E}_{2}$ induces a rise in sperm $\left[\mathrm{Ca}^{2+}\right]_{\mathrm{i}}$ and tyrosine phosphorylation of sperm proteins re-

Correspondence to: Dr Marco Rossato, Department of Medical and Surgical Sciences, Clinica Medica 3, University of Padova, Via Ospedale 105, 35128 Padova, Italy. Tel: +39-049-8218747; Fax: +39-049-8213332; E-mail: marco.rossato@unipd.it sulting in the inhibition of progesterone stimulated $\left[\mathrm{Ca}^{2+}\right]_{\mathrm{i}}$ increase and acrosome reaction [10]. Although the physiological trigger of sperm acrosome reaction in human sperm has not been clearly discovered, there is a general agreement in considering the oocyte ZP3 as the natural activator of sperm acrosomal exocytosis. Beside ZP3, a number of different agents have been shown to stimulate acrosome reaction in human sperm activating different signaling pathways [11 and references therein, 12]. In previous studies we demonstrated that extracellular ATP was a rapid and potent inducer of human sperm acrosome reaction through the interaction with a specific $\mathrm{P} 2 \mathrm{X}$ receptor expressed on sperm plasma membrane which activation activates an influx of $\mathrm{Na}^{+}$from the external medium and a plasma membrane depolarization leading to acrosome reaction and fertilizing ability acquisition $[13,14]$. It has been shown that $17 \beta E_{2}$ negatively modulates a wide range of biological effects in a number of different cell types through a non genomic mechanism of action and recently Darszon's group demonstrated that this steroid inhibits $\mathrm{Ca}^{2+}$ channels activity in mouse spermatogenetic cells [15-17]. In the present study we evaluated the effects of $17 \beta \mathrm{E}_{2}$ on extracellular ATP stimulated effects in human sperm. 


\section{Materials and methods}

\section{Materials}

Tamoxifen, $17 \beta \mathrm{E}_{2}, 17 \alpha \mathrm{E}_{2}$, pisum sativum-FITC, ATP, propidium iodide have been purchased by Sigma chemical Co (Milan, Italy). Fura-2/AM and bis-oxonol were obtained by Molecular Probes (Eugene, OR). All other chemicals were of analytical grade.

\section{Semen collection}

We evaluated five normozoospermic healthy men referring to our center because of semen donation. Semen culture was negative and antisperm antibodies were absent in all subjects. Nobody had a history of previous cryptorchidism, testicular torsion and genital tract infections.

\section{Experimental protocol}

Semen samples were collected after 3 days of sexual abstinence in sterile containers. After fluidification at room temperature for $30 \mathrm{~min}$, standard seminal parameters were examined according to the WHO laboratory manual [18]. All semen samples showed normal standard parameters. To evaluate the effects of $17 \beta \mathrm{E}_{2}$ on human sperm, isolated motile sperm semen samples were divided in two equivalent aliquots and then washed with BWW medium. After washing, each sperm sample was suspended in BWW at a concentration of $10 \times 10^{6} / \mathrm{ml}$ and incubated in the presence and absence of $17 \beta \mathrm{E}_{2}$ at different concentrations $(0.01,0.1$, 1.0 and $10.0 \mu \mathrm{M}$ ) for $120 \mathrm{~min}$. After incubation sperm viability, motility and acrosome reaction were evaluated. In separate experiments we evaluated the effects of $17 \beta \mathrm{E}_{2}$ $(1.0 \mu \mathrm{M})$ on sperm acrosome reaction induced by extracellular ATP $(2.5 \mathrm{mM})$. When evaluating the effects of $17 \beta \mathrm{E}_{2}$, some experiments were preceeded by sperm preincubation with the inactive stereoisomer $17 \alpha \mathrm{E}_{2}(1.0 \mu \mathrm{M})$ and with the $17 \beta \mathrm{E}_{2}$ receptor antagonist tamoxifen $(1.0 \mu \mathrm{M})$ for $15 \mathrm{~min}$ before $17 \beta \mathrm{E}_{2}$ addition.

\section{Evaluation of sperm motility and viability}

Sperm motility was assessed by means of light microscopy examining an aliquot of each sperm sample before and after incubation in the presence and absence of $17 \beta \mathrm{E}_{2}$ at different concentrations and extracellular ATP $(2.5 \mathrm{mM})$. Sperm motility was expressed as percentage of total motile sperm. Sperm viability was evaluated by means of redeosin exclusion test and expressed as percent of viable sperm. Both $17 \beta \mathrm{E}_{2}$ (up to the concentration of $10.0 \mu \mathrm{M}$ ) and ATP $(2.5 \mathrm{mM})$ did not significantly modify sperm motility and viability.

\section{$\left[\mathrm{Ca}^{2+}\right]_{i}$ measurement in human sperm}

$\left[\mathrm{Ca}^{2+}\right]_{\mathrm{i}}$ was measured utilizing the fluorescent probe fura2/AM as previously described [2]: sperm isolated as above were incubated for $30 \mathrm{~min}$ at $37^{\circ} \mathrm{C}$ in the presence of
fura-2/AM $(2 \mu \mathrm{M})$. After loading, sperm were washed by centrifugation at $800 \times g$ for $10 \mathrm{~min}$, resuspended in BWW medium and maintained at room temperature until used. $\left[\mathrm{Ca}^{2+}\right]_{\mathrm{i}}$ was measured in a LS50B Perkin Elmer fluorometer equipped with a thermostatted and magnetically-stirred cuvette holder and utilizing $1.0 \mathrm{ml}$ sperm aliquots. The excitation wavelenght was alternated between 350 and 380 $\mathrm{nm}$ and emission fluorescence was continuously monitored at $505 \mathrm{~nm}$.

\section{Evaluation of sperm plasma membrane potential changes}

Sperm plasma membrane changes were monitored utilizing the potential sensitive fluorescent dye bis-oxonol as previously described [13]. Briefly, $1.5 \times 10^{6}$ sperm were placed in a cuvette thermostatted at $37{ }^{\circ} \mathrm{C}$ containing the bis-oxonol solution $(200 \mathrm{nM})$ in saline. After stabilization of the fluorescent signal, additions of test substances were made. Excitation and emission wavelenghts were 540 and $580 \mathrm{~nm}$, respectively. In some experiments evaluating the role of the $17 \beta \mathrm{E}_{2}$ receptor antagonist tamoxifen and of the $\mathrm{K}^{+}$channel-blocker tetraethylammonium (TEA) on $17 \beta \mathrm{E}_{2}$ induced plasma membrane potential variations, sperm suspensions were pre-incubated with each specific blocker for $15 \mathrm{~min}$ before $17 \beta \mathrm{E}_{2}$ addition.

\section{Acrosomal status evaluation}

In preliminary experiments we tested the effects of different $17 \beta \mathrm{E}_{2}$ concentrations on $\left[\mathrm{Ca}^{2+}\right]_{\mathrm{i}}$ variations in human sperm and found that at $1.0 \mu \mathrm{M}$ the steroid exerted its maximal effects and then we utilized this concentration for the experiments evaluating sperm acrosome induction. Sperm acrosome reaction was evaluated after $120 \mathrm{~min}$ incubation in the presence and absence of $17 \beta \mathrm{E}_{2}(1.0 \mu \mathrm{M})$. In separate experiments we evaluated the effects of $17 \beta \mathrm{E}_{2}$ $(1.0 \mu \mathrm{M})$ on sperm acrosome reaction induced by extracellular ATP $(2.5 \mathrm{mM})$. When evaluating the effects of $17 \beta \mathrm{E}_{2}$, some experiments were preceeded by sperm preincubation with the estrogen receptor antagonist tamoxifen for 15 min before $17 \beta \mathrm{E}_{2}$ addition. The acrosomal status was evaluated utilizing FITC-conjugated pisum sativum agglutinin (PSA-FITC) and a flow cytometric analysis. In brief, after incubation in the different experimental conditions described above, sperm aliquots were incubated with PSA-FITC $(1.0 \mu \mathrm{g} / \mathrm{ml})$ for $30 \mathrm{~min}$ at $37^{\circ} \mathrm{C}$. Propidium iodide (PI, $10 \mu \mathrm{g} / \mathrm{ml}$ ) was added to each sperm suspension after 20 min from PSA-FITC addition and incubated for 10 min. After incubation each aliquot was washed with prewarmed PBS $\left(37^{\circ} \mathrm{C}\right)$ for $10 \mathrm{~min}$ at $600 \mathrm{~g}$. After washing, each sperm pellet was suspended in PBS and the flow cytometric analysis was performed by means of flow cytometry (FACSCAN, Becton \& Dickinson, Milan, Italy). Non viable sperm (PI positive) were detected using fluorescence detector 3 (FL3, detecting photons with a wavelength $>670 \mathrm{~nm}$ ) while acrosome reacted sperm (PSA-FITC-positive and PI negative) were detected using fluorescence detector 1 (FL1, detecting photons with a wavelength in the range $515-545 \mathrm{~nm}$ ). Non sperm events 
were gated out of the fluorimetric analysis as determined from the forward-scatter and side-scatter analysis. Ten thousand gated-events were recorded for each analysis.

\section{Statistical analysis}

Data are expressed as mean \pm S.D. and analysed using the Student's $t$-test and the analysis of variance (ANOVA, StatView, Abacus Concepts, Cary, NC, USA). A $P$ value $<$ 0.05 was chosen as the limit for statistical significance.

\section{Results}

\section{Effects of $17 \beta E_{2}$ on sperm $\left[\mathrm{Ca}^{2+}\right]_{i}$ and plasma membrane potential}

Stimulation of fura-2 loaded human sperm with $17 \beta \mathrm{E}_{2}$ induced a rapid and dose dependent $\mathrm{Ca}^{2+}$ rise that was sustained and completely dependent on the presence of $\mathrm{Ca}^{2+}$ in the external medium since it was abrogated by $\mathrm{Ca}^{2+}$ chelation with EGTA (Figure 1). The effects of $17 \beta \mathrm{E}_{2}$ on sperm plasma membrane potential variations have not been explored yet. Then we analyzed the modifications of sperm plasma membrane potential induced by $17 \beta \mathrm{E}_{2}$ utilizing the potential sensitive fluorescent dye bis-oxonol as previously described [13]. As shown in Figure 2 (trace a) $17 \beta \mathrm{E}_{2}$ induced a rapid plasma membrane hyperpolarization that was dependent on $\mathrm{K}^{+}$efflux from the sperm cytoplasm since when sperm were pre-incubated in the presence of TEA, a well known $\mathrm{K}^{+}$channel blocker, the plasma membrane hyperpolarization induced by $17 \beta \mathrm{E}_{2}$ was inhibited (Figure 2, trace b). Given the effects of $17 \beta \mathrm{E}_{2}$ on

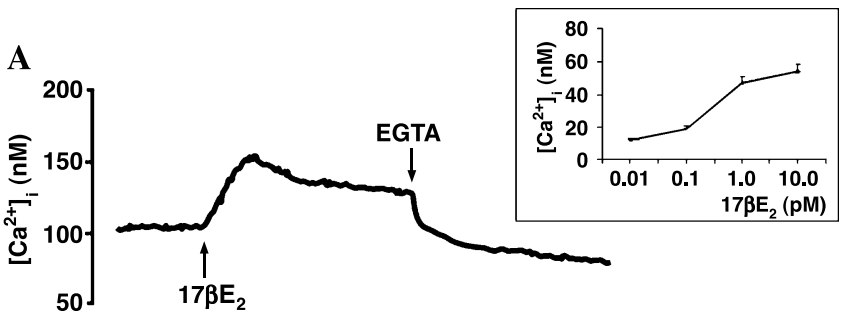

B

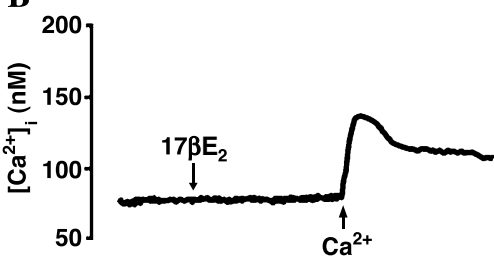

$\underline{2 \min }$

Figure 1. Effects of $17 \beta \mathrm{E}_{2}$ on $\left[\mathrm{Ca}^{2+}\right]_{\mathrm{i}}$ in human sperm. Isolated motile human sperm suspensions $\left(4.0-5.0 \times 10^{6}\right.$ cells $)$ were loaded with fura- $2 /$ $\mathrm{AM}$ as described in the Material and Methods section. (A) Sperm were suspended in $\mathrm{Ca}^{2+}$ containing medium. (B) Sperm were suspended in $\mathrm{Ca}^{2+}$ -free medium. Where indicated $17 \beta \mathrm{E}_{2}(1.0 \mu \mathrm{M})$, EGTA $(2.0 \mathrm{mM})$ and $\mathrm{Ca}^{2+}(2.0 \mathrm{mM})$ were added. Traces are representative of a typical experiment of three. Inset: dose response of $\left[\mathrm{Ca}^{2+}\right]_{\mathrm{i}}$ increase induced by increasing concentrations of $17 \beta \mathrm{E}_{2}(0.01,0.1,1.0$ and $10.0 \mu \mathrm{M})$ in human sperm. Results represent mean \pm S.D. of three separate experiments.

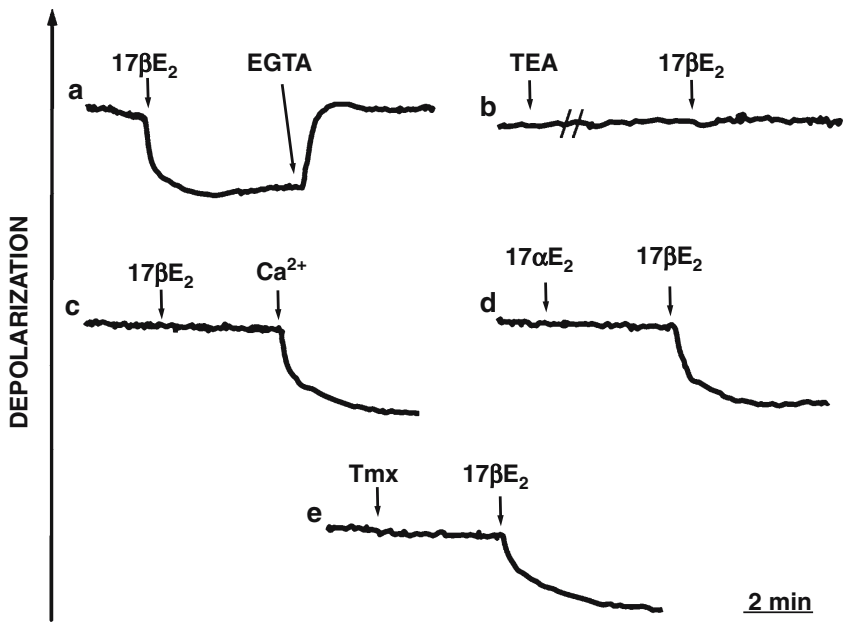

Figure 2. Effects of $17 \beta \mathrm{E}_{2}$ on sperm plasma membrane potential. Isolated motile human sperm $\left(1.5 \times 10^{6}\right.$ cells $)$ were suspended in the presence of $200 \mathrm{nM}$ bis-oxonol, as described in the Materials and methods section, in control medium (trace a), tetraethylammonium (TEA, $20 \mathrm{mM}$ ) containing medium and preincubated for 15 min before $17 \beta \mathrm{E}_{2}$ addition (trace $b$ ), $\mathrm{Ca}^{2+}$-free medium (trace $c$ ), $\mathrm{Ca}^{2+}$ containing medium (traces $d$ and $e$ ). Where indicated, $17 \mathrm{~B}_{2}(1.0 \mu \mathrm{M})$, EGTA $(2.0 \mathrm{mM})$, tetraethylammonium (TEA, $20 \mathrm{mM})$, calcium $\left(\mathrm{Ca}^{2+}, 2.0 \mathrm{mM}\right), 17 \alpha \mathrm{E}_{2}(1.0 \mu \mathrm{M})$ were added. Traces represent the result of a single from three similar experiments.

sperm $\left[\mathrm{Ca}^{2+}\right]_{\mathrm{i}}$ we analyzed the role of $\mathrm{Ca}^{2+}$ ions in $17 \beta \mathrm{E}_{2}$ induced plasma membrane hyperpolarization. When incubated in $\mathrm{Ca}^{2+}$-free medium, $17 \beta \mathrm{E}_{2}$ addition did not induced any plasma membrane potential variation (Figure 2, trace c) but when $\mathrm{Ca}^{2+}$ was added back to the sperm suspension a prompt plasma membrane hyperpolarization occurred demonstrating that the hyperpolarizing effects of $17 \beta \mathrm{E}_{2}$ were dependent on $\left[\mathrm{Ca}^{2+}\right]_{\mathrm{i}}$ rise induced by this steroid. The effects of $17 \mathrm{E}_{2}$ were specific since its inactive isomer $17 \alpha \mathrm{E}_{2}$ did not induce any increase in $\left[\mathrm{Ca}^{2+}\right]_{\mathrm{i}}$ (not shown) nor any modification of sperm plasma membrane potential at the concentration of $1.0 \mu \mathrm{M}$ without modifing the effects of $17 \beta \mathrm{E}_{2}$ (Figure 2, trace d). Furthermore the rapid plasma membrane hyperpolarizing effects of $17 \beta \mathrm{E}_{2}$ were not inhibited by sperm pre-incubation with tamoxifen, a well known antagonist of the classic receptor for $17 \beta \mathrm{E}_{2}$ (Figure 2 , trace e).

Effects of $17 \beta E_{2}$ on plasma membrane potential variations induced by extracellular ATP

We have previously demonstrated that extracellular ATP activates human sperm inducing a rapid plasma membrane depolarization depending on an influx of $\mathrm{Na}^{+}$from the extracellular medium. In Figure 3 (trace a) it is shown that extracellular ATP induces a rapid plasma membrane depolarization confirming previous data [13]. The depolarizing effects of ATP were not maximal since gramicidin $\mathrm{D}$, a polypeptide antibiotic that forms pores in the cell membrane allowing $\mathrm{Na}^{+}$to enter the cell thus inducing plasma membrane depolarization [19], was able to further depolarize plasma membrane potential (Figure 3, trace a). The addition of $17 \beta \mathrm{E}_{2}(1.0 \mu \mathrm{M})$ to sperm suspension just 


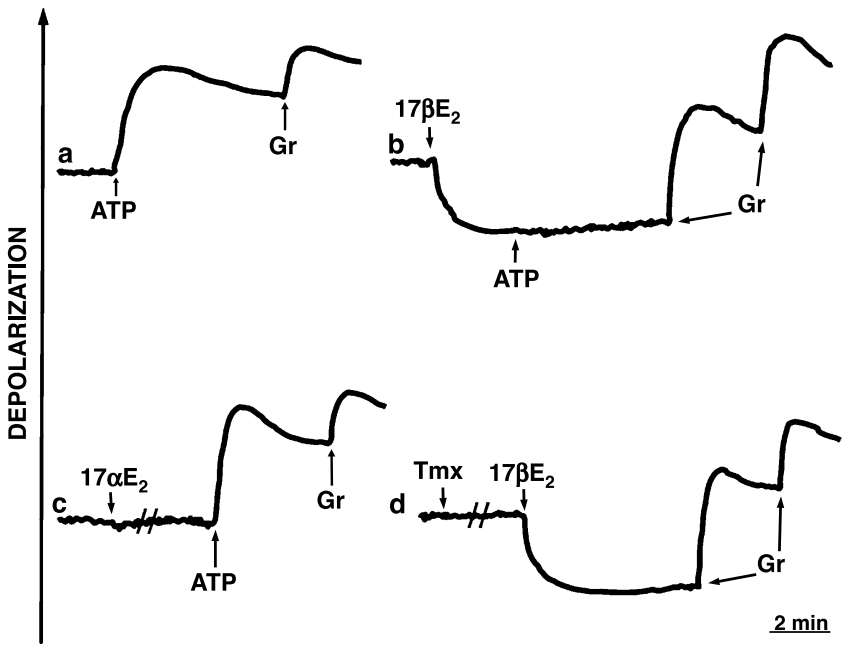

Figure 3. Effects of $17 \mathrm{E}_{2}$ on ATP induced sperm plasma membrane potential variations. Isolated motile human sperm $\left(1.5 \times 10^{6}\right.$ cells $)$ were suspended in the presence of $200 \mathrm{nM}$ bis-oxonol as described in the Material and Methods section in calcium containing medium before addition of the different agonists. Where indicated ATP $(2.5 \mathrm{mM})$, gramicidin $\mathrm{D}(\mathrm{Gr}, 1.0 \mu \mathrm{M}), 17 \beta \mathrm{E}_{2}(1.0 \mu \mathrm{M}), 17 \alpha \mathrm{E}_{2}(1.0 \mu \mathrm{M})$ and tamoxifen $(1.0 \mu \mathrm{M})$ were added. Traces represent the result of a single from three similar experiments.

before stimulation with extracellular ATP inhibited the ATP induced plasma membrane depolarization (Figure 3, trace b) wih an $\mathrm{IC}_{50}$ of about $0.1 \mu \mathrm{M}$ (Figure 4). The inhibitory effects of $17 \beta \mathrm{E}_{2}$ were so rapid that it is not possible to ascribe them to the classical genomic action of the steroid but to a non genomic rapid effect via the activation of putative receptors located on the sperm plasma membrane as previously suggested [20-22]. The effects of $17 \beta \mathrm{E}_{2}$ in reducing the effects of extracellular ATP in human sperm were specific since its inactive isomer $17 \alpha \mathrm{E}_{2}$ was not effective (Figure 3, trace c). Preincubation of sperm in the presence of the classic $17 \beta \mathrm{E}_{2}$

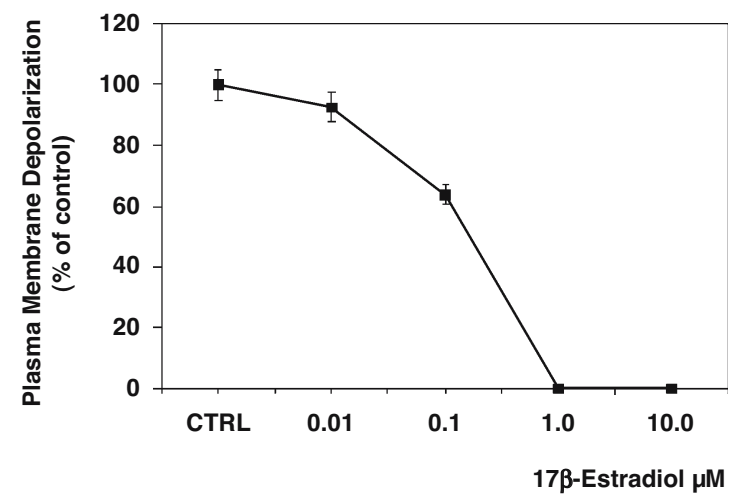

Figure 4. Dose dependence of the inhibition by $17 \beta \mathrm{E}_{2}$ of the ATP induced plasma membrane depolarization in human sperm. Isolated sperm were suspended in the presence of $200 \mathrm{nM}$ bis-oxonol as described in the Materials and methods section. Sperm suspensions were stimulated with $17 \beta \mathrm{E}_{2}$ at different doses $(0.01,0.1,1.0$ and $10.0 \mu \mathrm{M})$ for $2 \mathrm{~min}$ before addition of ATP (2.5 mM). Plasma membrane depolarization is expressed as percentage of the plasma membrane depolarization induced by ATP determined in the absence of $17 \beta \mathrm{E}_{2}(100 \%)$. Results are mean \pm S.D. of three separate experiments.

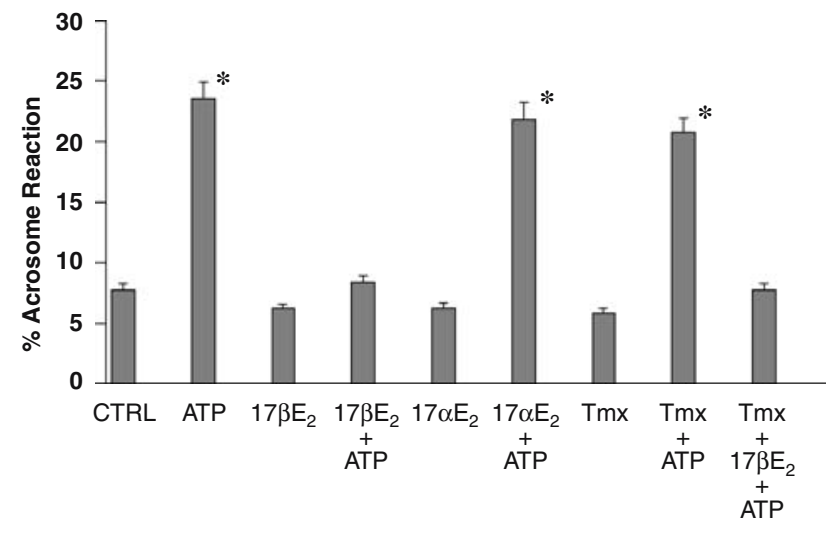

Figure 5. Effects of $17 \beta \mathrm{E}_{2}$ on ATP induced acrosome reaction in human sperm. Isolated motile human sperm were incubated for $120 \mathrm{~min}$ in control medium (CTRL) and in the presence of ATP $(2.5 \mathrm{mM})$ with and without the presence of $17 \beta \mathrm{E}_{2}(1.0 \mu \mathrm{M}), 17 \alpha \mathrm{E}_{2}$ or tamoxifen (Tmx, 1.0 $\mu \mathrm{M})$. Data are expressed as mean \pm S.D. of results from three separate experiments. $* P<0.01$ vs control and samples treated with $17 \beta \mathrm{E}_{2}$.

genomic receptor inhibitor tamoxifen did not modify the effects of $17 \beta \mathrm{E}_{2}$ on sperm plasma membrane thus confirming that the action of this steroid in human sperm are not due to the interaction with its classical cytoplasmic receptor (Figure 3, trace d).

\section{Effects of $17 \beta E_{2}$ on basal and extracellular ATP stimulated acrosome reaction}

Previous results from other Authors have clearly shown that $17 \beta \mathrm{E}_{2}$ did not influence acrosomal loss [10, 23]. Furthermore we demonstrated that extracellular ATP rapidly induced acrosomal exocytosis in mammalian and human sperm $[5,13,24-26]$. The results of the present study confirm those previous observations and demonstrate that $17 \beta \mathrm{E}_{2}$ inhibits sperm acrosome reaction induced by extracellular ATP while the inactive steroisomer $17 \alpha \mathrm{E}_{2}$ was without effect (Figure 5). The non genomic feature of $17 \beta \mathrm{E}_{2}$ action on human sperm was further confirmed by the lack of any effect of the classic $17 \beta \mathrm{E}_{2}$ genomic receptor antagonist tamoxifen on the inhibitory action of $17 \beta \mathrm{E}_{2}$ on ATP-induced acrosome reaction (Figure 5).

\section{Discussion}

The results of the present study confirm that $17 \beta \mathrm{E}_{2}$ rapidly increases $\left[\mathrm{Ca}^{2+}\right]_{\mathrm{i}}$ in human sperm as previously demonstrated [10] and extend our knowledge on the rapid non genomic effects of this steroid in human sperm showing for the first time that it induces a rapid plasma membrane hyperpolarization that is dependent on the influx of $\mathrm{Ca}^{2+}$ from the external medium that activates an efflux of $\mathrm{K}^{+}$ ions from the sperm cytoplasm. The existence of $\mathrm{Ca}^{2+}$ activated $\mathrm{K}^{+}$channels in human sperm has been previously reported [27] and the plasma membrane hyperpolarizing effects of the different agonists reported so far have been shown to inhibit important sperm functions by modifing sperm responsiveness to putative physiological inducers 
of the acrosome reaction [28 and references therein]. The other main result of the present study is the demonstration that $17 \beta \mathrm{E}_{2}$ inhibits sperm plasma membrane depolarization and acrosome reaction induced by extracellular ATP, a putative physiological activator of human sperm acting through a still poorly characterized $\mathrm{P} 2 \mathrm{X}$ receptor subtype $[5,13] .17 \beta \mathrm{E}_{2}$ itself did not induce any increase of sperm acrosome reaction despite the fact that it enhances $\left[\mathrm{Ca}^{2+}\right]_{\mathrm{i}}$ but probably other mechanisms, that are not activated by $17 \beta \mathrm{E}_{2}$, are involved in the induction of acrosomal exocytosis other than $\left[\mathrm{Ca}^{2+}\right]_{\mathrm{i}}$ increase.

Purinergic receptors are classified in two families, P2X and P2Y. The P2Y family encompasses a number of different receptors activated by ATP but also by other nucleotides and are linked to inositol phosphate and diacylglycerol formation leading to $\mathrm{Ca}^{2+}$ leakage from intracellular stores and protein kinase $\mathrm{C}$ activation $[29,30]$. These purinergic receptors have not been identified in human sperm yet [13] although their presence in mammalian male reproductive tract has been reported $[24,31]$. The other P2 purinergic receptor family is the $\mathrm{P} 2 \mathrm{X}$ constituted by different multimeric ligand-gated ion channels activated by ATP and allowing the passage of small ions as well as $\mathrm{Ca}^{2+}$ and $\mathrm{Na}^{+}$ inducing increases in $\left[\mathrm{Ca}^{2+}\right]_{\mathrm{i}}$ and plasma membrane depolarization. This subgroup comprises seven different subtypes (named P2X1 to P2X7) and are activated by ATP [32]. In human sperm extracellular ATP does not induce any modification of $\left[\mathrm{Ca}^{2+}\right]_{\mathrm{i}}$ thus probably excluding the presence of P2Y receptor subtype in these cells. On the contrary this nucleotide induced a rapid plasma membrane depolarization due to the activation of a $\mathrm{Na}^{+}$-permeable channel as previously demonstrated $[5,13]$.

The effects of $17 \beta \mathrm{E}_{2}$ on human sperm were rapid, stereospecific and not inhibited by the classic nuclear estrogen receptor antagonist tamoxifen. All these characteristics, together with the knowledge that mature sperm do not retain protein synthesis activity [33], confirm that the effects of $17 \beta \mathrm{E}_{2}$ in human sperm are non genomic. The rapid, non genomic hyperpolarizing effects of $17 \beta \mathrm{E}_{2}$ have been previously described in neurons from pre-optic area where this steroid inhibits their excitability by inducing a plasma membrane hyperpolarization due to the opening of $\mathrm{K}^{+}$channel thus reducing their firing rate $[34,35] .17 \beta \mathrm{E}_{2}$ has been shown to induce plasma membrane hyperpolarization also in hypothalamic GnRH neurons in guinea pig [36]. From this point of view the similarity of the spermatozoon with "a neuron with the tail" as suggested recently by Stanley Meizel is further underlined considering the similar effects of $17 \beta \mathrm{E}_{2}$ on cell plasma membrane [37]. Previous studies have identified sperm plasma membrane for progesterone and in the present study we show rapid effects of $17 \beta \mathrm{E}_{2}$ in human sperm thus hypothizing the presence of binding sites also for this steroid on human sperm surface as previously suggested [10]. The membrane receptors for $17 \beta \mathrm{E}_{2}$ mediating rapid non genomic effects in human sperm appear to be molecularly and pharmacologically different from the classical intracellular $17 \mathrm{E}_{2}$ receptors. On the other hand it has been demonstrated that in ERKO mice $17 \beta \mathrm{E}_{2}$ actions appear to be genetically and pharmacologically different from those of the classic $17 \beta \mathrm{E}_{2}$ receptor thus supporting the hypothesis that $17 \beta \mathrm{E}_{2}$ possess also non genomic actions although some discordant data exist $[38,39]$.

In mammals, $17 \beta \mathrm{E}_{2}$ influences neuronal activity via non genomic mechanism of action by changing the cellular responsiveness to the activation of different receptor systems to their respective agonist [40]. Indeed this was the case also for the effects of extracellular ATP in human sperm that were specifically inhibited by $17 \beta \mathrm{E}_{2}$. The inhibitory action of $17 \beta \mathrm{E}_{2}$ on extracellular ATP induced effects are not novel since $17 \mathrm{E}_{2}$ has been previously shown to inhibit the response to extracellular ATP in neurons [41], in PC12 [42] and kidney cells [43] and were suggested to be due to interference with ion channels.

Recently it has been suggested that $17 \beta \mathrm{E}_{2}$ inhibitory action on ATP stimulated effects were due to $\mathrm{P} 2$ purinergic receptor inhibition [42] although a role of plasma membrane potential variations or alterations of plasma membrane physical properties have been suggested $[10,15]$. This could be the case also for human sperm since $17 \beta \mathrm{E}_{2}$ has been previously shown to attenuate the stimulatory effects of different agonists in human sperm and mammalian spermatogenic cells $[10,15]$ and in a number of other cellular systems [41-43]. Activation of P2 purinergic receptors by extracellular ATP in human sperm induced $\mathrm{Na}^{+}$influx, plasma membrane depolarization and acrosome reaction through the activation of a not yet identified P2X purinergic receptor subtype $[5,13]$. To this respect it is of interest that $17 \mathrm{E}_{2}$ seems to exert its inhibitory actions just interfering with $\mathrm{P} 2 \mathrm{X}$ receptor subtype as demonstrated by Tourmaniaz et al. [43]. However we cannot completely rule out the possibility that $17 \beta \mathrm{E}_{2}$ might directly interact with $\mathrm{Na}^{+}$channel (as for $\mathrm{Ca}^{2+}$ channels) or the P2X receptor activated by extracellular ATP.

The possible interference of $17 \beta \mathrm{E}_{2}$ with $\mathrm{Na}^{+}$channel coupled to P2X receptor activation by extracellular ATP appears to be a novel finding although further studies are required to corroborate this hypothesis. To this regard it has to be remembered that the activity of membrane spanning proteins, as plasma membrane ion channels, is regulated also by the physical properties of the plasma membrane lipid bilayer via lipid-protein interactions $[15$, 44-46]. Very recently some Authors have described that plasma membrane $\mathrm{Na}^{+}$channel function is regulated by protein (channel)-lipid bilayer hydrophobic interactions $[44,45]$. Then it is also possible that $17 \beta \mathrm{E}_{2}$, a highly hydrophobic molecule, might modify the ATP-gated $\mathrm{Na}^{+}-$ channel through its interaction with the plasma membrane lipid bilayer. This hypothesis could be further supported by the fact that $17 \beta \mathrm{E}_{2}$ concentrations required for fully influencing sperm functions in vitro are quite higher than physiological plasma levels of this hormone above all in men. However we have to consider that $17 \beta \mathrm{E}_{2}$ concentrations within the testis are about 75 times higher than plasma levels and that seminal plasma levels of $17 \beta \mathrm{E}_{2}$ are higher than those of serum [47]. Together with the demonstration that human sperm possess a biologically active aromatase, the enzyme responsible for the aromati- 
zation of testosterone to estradiol [48] it is conceivable that sperm are exposed to elevated $17 \beta \mathrm{E}_{2}$ concentrations from the site they are produced within the testis and along the whole male reproductive tract. Furthermore we have also to consider $17 \beta \mathrm{E}_{2}$ concentrations within the female genital tract secretions where sperm are spawn after ejaculation and that, at the time of ovulation, are close to $17 \beta \mathrm{E}_{2}$ concentrations utilized in the present study [10]. Finally the effects of $17 \beta \mathrm{E}_{2}$ on sperm functions may be further amplified during ovarian hyperstimulation when $17 \beta \mathrm{E}_{2}$ plasma levels are much higher than those found in situations of unstimulated follicular growth as during spontaneous ovulation. Then it appears that during their trip to the oocyte, sperm are costantly exposed to different $17 \beta \mathrm{E}_{2}$ concentrations negatively modulating its functions. Thus it could be possible that some forms of infertility might be due to interferences of $17 \beta \mathrm{E}_{2}$ with the physiological mechanisms leading to oocyte fertilization. To this regard an increase in $17 \beta \mathrm{E}_{2}$ concentrations has previously described in seminal plasma of infertile men [47].

In conclusion the present study demonstrates that $17 \beta \mathrm{E}_{2}$ interferes with ATP-dependent activation of human sperm through non genomic mechanisms of action suggesting a possible physiopathological role of this steroid in some forms of infertility.

\section{References}

1. Blackmore PF, Neulen J, Lattanzio F et al. Cell surface-binding sites for progesterone mediate calcium uptake in human sperm. J Biol Chem 1991; 266: 18655-9.

2. Foresta C, Rossato M, Di Virgilio F. Ion fluxes through the progesterone-activated channel of the sperm plasma membrane. Biochem J 1993; 294: 279-83.

3. Baldi E, Falsetti C, Krausz C et al. Stimulation of platelet-activating factor synthesis by progesterone and A23187 in human spermatozoa. Biochem J 1993; 292: 209-16.

4. Thomas P, Meizel S. Phosphatidylinositol 4,5-bisphosphate hydrolysis in human sperm stimulated with follicular fluid or progesterone is dependent upon $\mathrm{Ca}^{2+}$ influx. Biochem J 1989; 264: 539-46.

5. Foresta C, Rossato M, Chiozzi P et al. Mechanism of human sperm activation by extracellular ATP. Am J Physiol 1996; 270: C1709-14

6. Patrat C, Serres C, Jouannet P. Induction of a sodium ion influx by progesterone in human spermatozoa. Biol Reprod 2000; 62: 1380-6.

7. Garcia MA, Meizel S. Importance of sodium ion to the progesteroneinitiated acrosome reaction in human sperm. Mol Reprod Dev 1996; 45: 513-20.

8. Wassarman PM. Sperm receptors and fertilization in mammals. Mt Sinai J Med 2002; 69: 148-55.

9. Lobo RA, diZerega GS, Marrs RP. Follicular fluid steroid levels in dysmature and mature follicles from spontaneous and hyperstimulated cycles in normal and anovulatory women. J Clin Endocrinol Metab 1985; 60: 81-7.

10. Luconi M, Muratori M, Forti G et al. Identification and characterization of a novel functional estrogen receptor on human sperm membrane that interferes with progesterone effects. J Clin Endocrinol Metab 1999; 84: 1670-8.

11. Breitbart H. Signaling pathways in sperm capacitation and acrosome reaction. Cell Mol Biol 2003; 49: 321-7.

12. Baldi E, Luconi M, Bonaccorsi L et al. Signal transduction pathways in human spermatozoa. J Reprod Immunol 2002; 53: 121-31.

13. Foresta C, Rossato M, Di Virgilio F. Extracellular ATP is a trigger for the acrosome reaction in human spermatozoa. J Biol Chem 1992; 267: 19443-7.

14. Rossato M, La Sala GB, Balasini M et al. Sperm treatment with extracellular ATP increases fertilization rates in in-vitro fertilization for male factor infertilità. Hum Reprod 1999; 14: 694-7.

15. Espinosa F, Lopez-Gonzalez I, Munoz-Garay C et al. Dual regulation of the T-type $\mathrm{Ca}^{2+}$ current by serum albumin and $\beta$ estradiol in mammalian spermatogenic cells. FEBS Lett 2000; 475: 251-6.

16. Lee DY, Chai YG, Lee EB et al. 17ß-estradiol inhibits high-voltageactivated calcium channel currents in rat sensory neurons via a nongenomic mechanism. Life Sci 2002; 70: 2047-59.

17. Okabe $\mathrm{K}$, Okamoto $\mathrm{F}$, Kajiya $\mathrm{H}$ et al. Estrogen directly acts on osteoclasts via inhibition of inward rectifier $\mathrm{K}^{+}$channels. Naunyn Schmiedebergs Arch Pharmacol 2000; 361: 610-20.

18. WHO. WHO Laboratory Manual for the Examination of Human Semen and Sperm-Cervical Mucus Interaction. Cambridge: Cambridge University Press 1999

19. Wallace BA. Gramicidin channels and pores. Annu Rev Biophys Biophys Chem 1990; 19: 127-57.

20. Hernandez-Perez O, Ballesteros LM, Rosado A. Binding of 17-betaestradiol to the outer surface and nucleus of human spermatozoa. Arch Androl 1979; 3: 23-9.

21. Cheng CY, Boettcher B, Rose RJ et al. The binding of sex steroids to human spermatozoa. An autoradiographic study. Int J Androl 1981; 4: 1-17.

22. Durkee TJ, Mueller M, Zinaman M. Identification of estrogen receptor protein and messenger ribonucleic acid in human spermatozoa. Am J Obstet Gynecol 1998; 178: 1288-97.

23. Baldi E, Luconi M, Muratori $\mathrm{M}$ et al. A novel functional estrogen receptor on human sperm membrane interferes with progesterone effects. Mol Cell Endocrinol 2000; 161: 31-5.

24. Luria A, Rubinstein S, Lax Y et al. Extracellular adenosine triphosphate stimulates acrosomal exocytosis in bovine spermatozoa via P2 purinoceptor. Biol Reprod 2002; 66: 429-37.

25. Skiba-Lahiani M, Auger J, Terribile J et al. Stimulation of movement and acrosome reaction of human spermatozoa by PC12 liposomes encapsulating ATP. Int J Androl 1995; 18: 287-94.

26. Tomiyama T, Ohashi K, Tsutsui $\mathrm{T}$ et al. Acrosome reaction induced in a limited population of human spermatozoa by progesterone $\left(\mathrm{Ca}^{2+}\right.$-dependent $)$ and ATP $\left(\mathrm{Ca}^{2+}\right.$-independent $)$. Hum Reprod 1995; 10: 2052-5.

27. Rossato M, Di Virgilio F, Rizzuto R et al. Intracellular calcium store depletion and acrosome reaction in human spermatozoa: Role of calcium and plasma membrane potential. Mol Hum Reprod 2001; 7 : 119-28.

28. Neill AT, Vacquier VD. Ligands and receptors mediating signal transduction in sea urchin spermatozoa. Reproduction 2004; 127 : 141-9.

29. Ralevic V, Burnstock G. Receptors for purines and pyrimidines. Pharmacol Rev 1998; 50: 413-92.

30. Ziganshin AU, Ziganshina LE, Burnstock G. P2 receptors: Theoretical background for the use in clinical practice. Bull Exp Biol Med 2002; 134: 313-7.

31. Shariatmadari R, Sipila P, Vierula $\mathrm{M}$ et al. Adenosine triphosphate induces $\mathrm{Ca}^{2+}$ signal in epithelial cells of the mouse caput epididymis through activation of $\mathrm{P} 2 \mathrm{X}$ and $\mathrm{P} 2 \mathrm{Y}$ purinergic receptors. Biol Reprod 2003; 68: 1185-92.

32. Bean BP, Friel DD. ATP-activated channels in excitable cells. Ion Channels 1990; 2: 169-203.

33. Aquila S, Sisci D, Gentile M et al. Estrogen receptor (ER) alpha and ER beta are both expressed in human ejaculated spermatozoa: Evidence of their direct interaction with phosphatidylinositol-3-OH kinase/Akt pathway. J Clin Endocrinol Metab 2004; 89: 1443-51.

34. Wagner EJ, Reyes-Vazquez C, Rønnekleiv OK. The role of intrinsic and agonist-activated conductances in determining the firing patterns of preoptic area neurons in the guinea pig. Brain Res 2000; 879: 29-41.

35. Wagner EJ, Rønnekleiv OK, Kelly MJ. The noradrenergic inhibition of an apamin-sensitive, small conductance $\mathrm{Ca}^{2+}$-activated $\mathrm{K}^{+}$ 
channel in hypothalamic gamma-aminobutyric acid neurons: Pharmacology, estrogen sensitivity and relevance to the control of the reproductive axis. J Pharmacol Exp Ther 2001; 299: 21-30.

36. Lagrange AH, Rønnekleiv OK, Kelly MJ. Estradiol-17ß, and $\mu$-opioid peptides rapidly hyperpolarize GnRH neurons: A cellular mechanism of negative feedback. Endocrinology 1995; 136: 2341-4.

37. Meizel S. The sperm, a neuron with a tail: Neuronal receptors in mammalian sperm. Biol Rev Camb Philos Soc 2004; 79: 713-32.

38. Singh M, Setalo G Jr, Guan X et al. Estrogen-induced activation of the mitogen-activated protein kinase cascade in the cerebral cortex of estrogen receptor-alpha knock-out mice. J Neurosci 2000; 20: 1694-700.

39. Abraham IM, Todman MG, Korach KS et al. Critical in vivo roles for classical estrogen receptors in rapid estrogen actions on intracellular signaling in mouse brain. Endocrinology 2004; 145: 3055-61.

40. Kelly MJ, Qiu J, Wagner EJ et al. Rapid effects of estrogen on G protein-coupled receptor activation of potassium channels in the central nervous system (CNS). J Steroid Biochem Mol Biol 2003; 83: 187-93.

41. Chaban VV, Mayer EA, Ennes HS. Estradiol inhibits ATP-induced intracellular calcium concentration increase in dorsal root ganglia neurons. Neuroscience 2003; 118: 941-8.
42. Kim YJ, Hur EM, Park TJ et al. Nongenomic inhibition of catecholamine secretion by $17 \beta$-estradiol in PC12 cells. J Neurochem 2000; 74: 2490-6.

43. Cario-Toumaniantz C, Loirand G, Ferrier L et al. Non-genomic inhibition of human P2X7 purinoceptor by 17beta-oestradiol. J Physiol 1998; 508: 659-66.

44. Andersen OS, Nielsen C, Maer AM et al. Ion channels as tools to monitor lipid bilayer-membrane protein interactions: Gramicidin channels as molecular force transducers. Methods Enzymol 1999; 294: 208-24.

45. Lundbaek JA, Birn P, Hansen AJ. Regulation of sodium channel function by bilayer elasticity: The importance of hydrophobic coupling. Effects of Micelle-forming amphiphiles and cholesterol. J Gen Physiol 2004; 123: 599-621.

46. Bezrukov SM. Functional consequences of lipid packing stress. Curr Opin Colloid Interface Sci 2000; 5: 237-43.

47. Luboshitzky R, Kaplan-Zverling M, Shen-Orr Z et al. Seminal plasma androgen/oestrogen balance in infertile men. Int $\mathrm{J}$ Androl 2002; 25: 345-51.

48. Aquila S, Sisci D, Gentile ME et al. Human ejaculated spermatozoa contain active P450 aromatase. J Clin Endocrinol Metab 2002; 87: 3385-90. 